\title{
International Consensus Statement on Screening, Diagnosis and Treatment of Substance Use Disorder Patients with Comorbid Attention Deficit/Hyperactivity Disorder
}

\author{
Cleo L. Crunelle ${ }^{a, b}$ Wim van den Brink ${ }^{c}$ Franz Moggid \\ Maija Konstenius ${ }^{\mathrm{e}}$ Johan Franck ${ }^{\mathrm{e}}$ Frances R. Levin ${ }^{f}$ Geurt van de Glind ${ }^{g}$ \\ Zsolt Demetrovics $^{\mathrm{h}}$ Corné Coetzee ${ }^{\mathrm{i}}$ Mathias Luderer ${ }^{\mathrm{j}}$ Arnt Schellekens $^{\mathrm{k}}$ \\ ICASA consensus group Frieda Matthys ${ }^{\text {a }}$
}

\begin{abstract}
${ }^{a}$ Department of Psychiatry, Vrije Universiteit Brussel (VUB), Universitair Ziekenhuis Brussel (UZ Brussel), Brussels, Belgium; ${ }^{b}$ Toxicological Center, Antwerp University, Antwerp, Belgium; ' ${ }^{\mathrm{C}}$ Amsterdam Institute of Addiction Research

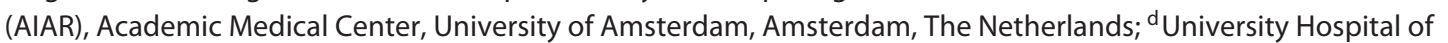

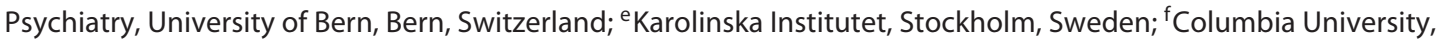
New York State Psychiatric Institute, New York, NY, USA; ${ }^{9}$ ICASA Foundation, University of Amsterdam, Amsterdam, The Netherlands; ' Eötvös Loránd University, Budapest, Hungary; 'Department of Pharmacy, University of Limpopo, Sovenga, South Africa; jDepartment of Addictive Behaviour and Addiction Medicine, Central Institute of Mental

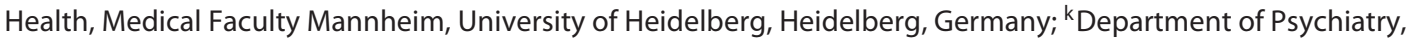
Radboudumc, Donders Institute for Brain, Cognition and Behavior, Nijmegen Institute for Scientist Practitioners in Addiction (NISPA), Nijmegen, The Netherlands
\end{abstract}

\section{Keywords}

Attention deficit/hyperactivity disorder · Substance use disorders · Diagnosis · Treatment · Consensus

\footnotetext{
Abstract

Adult attention deficit/hyperactivity disorder (ADHD) often co-occurs with substance use disorders (SUD) and is associated with early onset and more severe development of SUD and with reduced treatment effectiveness. Screening tools allow for a good recognition of possible ADHD in adults with SUD and should be used routinely, followed by an ADHD diagnostic process initiated as soon as possible. Simultaneous and integrated treatment of ADHD and SUD, using a combi-
}

nation of pharmaco- and psychotherapy, is recommended. Long-acting methylphenidate, extended-release amphetamines, and atomoxetine with up-titration to higher dosages may be considered in patients unresponsive to standard doses. This paper includes evidence- and consensus-based recommendations developed to provide guidance in the screening, diagnosis and treatment of patients with ADHDSUD comorbidity.

(C) 2018 S. Karger AG, Basel

The ICASA consensus group: Evaristo Akerele, Csaba Barta, Christoffer Brynte, Søren Dalsgaard, Geert Dom, Stephen Faraone, Máté Kapitány-Fövény, Sharlene Kaye, Carol Lim, Maria Paraskevopoulou, Maria Velez Pastrana, Mara Richman, Henk-Jan Seesink, Arvid Skutle, Katelijne van Emmerik-van Oortmerssen, Sofie Verspeet.

\section{KARGER}

(c) 2018 S. Karger AG, Basel

E-Mail karger@karger.com

www.karger.com/ear
Cleo L. Crunelle, PhD

Department of Psychiatry, University Hospital Brussels (UZ Jette)

Laarbeeklaan 101

Jette, BE-1090 Brussels (Belgium)

E-Mail cleo.crunelle@ gmail.com 


\section{Introduction}

\section{Comorbidity of Attention Deficit/Hyperactivity}

Disorder and Substance Use Disorders

Attention deficit/hyperactivity disorder (ADHD) is a childhood neurodevelopmental disorder that can persist into adulthood [1]. ADHD is strongly associated with the development of substance use disorders (SUD), often at a very early age and with a faster transition from less severe to more serious SUD [2]. Patients with ADHD-SUD comorbidity show more complex and chronic patterns of substance use, including more poly-substance use, than adults with SUD without comorbid ADHD [1,3]. They also present with greater psychiatric comorbidity, such as antisocial personality disorder, borderline personality disorder, anxiety disorders, bipolar disorders and/or post-traumatic stress disorders [4]. Despite being in treatment more often, adults with ADHD-SUD comorbidity have more difficulties remaining abstinent [5] and report a reduced quality of life with more professional, social and personal problems [6]. On a pharmacological level, several studies report lower effectiveness of standarddose pharmacotherapy for the treatment of ADHD in patients with ADHD-SUD comorbidity [7].

In summary, ADHD-SUD comorbidity is associated with multiple problems and reduced effectiveness of standard treatments, making proper diagnosis and successful treatment in adults with ADHD and SUD a challenge.

\section{Prevalence of $A D H D$ and SUD}

ADHD is associated with an increased risk of developing SUD later in life [8]. ADHD-SUD comorbidity is highly prevalent in addiction care: in a meta-analysis of 29 studies, $23.1 \%$ of patients with SUD also had adult ADHD [9]. The prevalence of ADHD depends on the type of substance of abuse, the setting (e.g., outpatient versus inpatient) and the diagnostic procedure (e.g., screening questionnaire versus structured clinical interview). In a large international study, $13.9 \%$ of treatment seeking SUD patients had a DSM-IV diagnosis of adult ADHD [10]. Age, gender, ethnicity and primary substance of abuse do not seem to systematically impact the prevalence rate of ADHD in SUD patients [10].

\section{Aim and Objective of the Consensus Statement}

This consensus statement was developed as a practical guide to assist professionals with the screening, diagnosis and treatment of adult patients with SUD and ADHD. The consensus statement is for patients and clinicians:

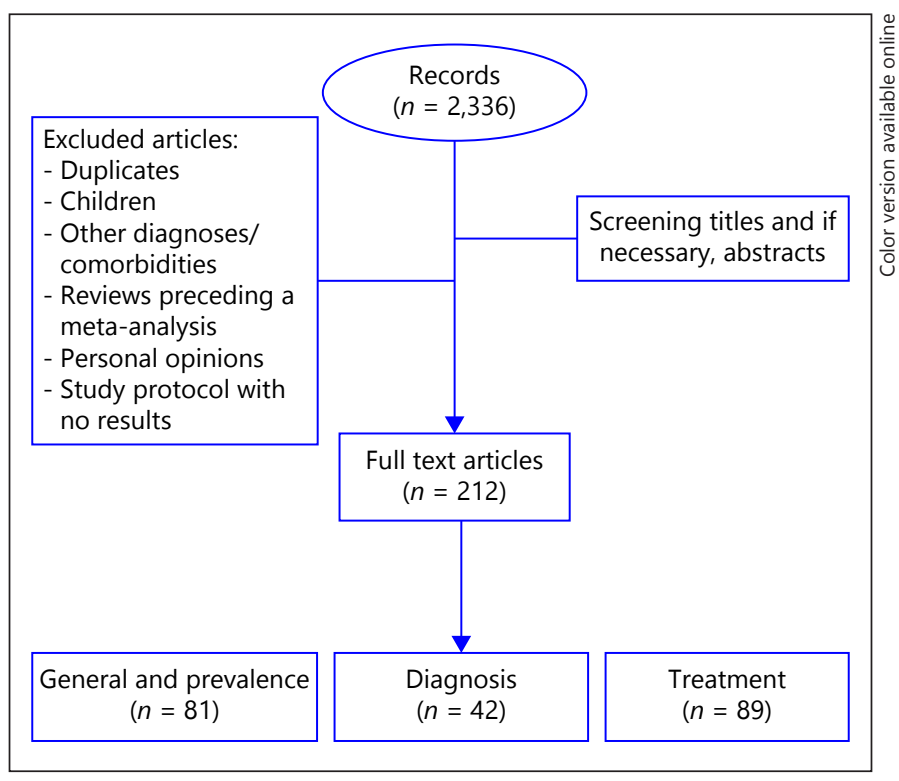

Fig. 1. Flowchart showing the search results.

general practitioners, psychiatrists, psychologists and other health professionals involved with alcohol and/or drug-dependent patients.

\section{Methods}

PubMed, Cinahl and Psychinfo were searched for articles published January 1994 to December 2015 using the terms "drug abuse," "substance use," "addiction," "dependence" and "ADHD," limited to articles published in English, French and Dutch. Simultaneously, we searched for existing guidelines in Clinical Evidence, CEBAM, NHS Guideline finder, Cochrane library, NICE, National Guideline Clearinghouse and GIN database. All retrieved articles and relevant cross-references were reviewed.

A flowchart of the search of articles is presented in Figure 1. Publications were discarded if they did not include adults; if ADHD or SUD was not the primary diagnosis; if they were reviews prior to a meta-analysis; if they were personal opinion papers; and if they were study protocols. The statements in this consensus text are based primarily on scientific evidence from available publications ( $n=212$; online suppl. Material 1, see www.karger.com/ doi/10.1159/000487767). When scientific evidence was lacking, a consensus was sought from the opinions of experts in the field, which is stated specifically in the main text when this was the case. To provide guidance on the strength of the evidence, the final recommendations summarized in Table 1 are assigned a rating based on the evidence quality score from the SIGN grading system. In the addendum to this main text, the full list of references that constitute the basis of this consensus statement can be found.

This consensus statement covers 2 main topics, (i) screening and diagnosis of ADHD and SUD and (ii) treatment of ADHD and SUD. This consensus statement was primarily developed from the perspective of adults with SUD and underlying ADHD, assessed in
Crunelle et al. 
Table 1. Tools for screening ADHD in individuals with comorbid SUD

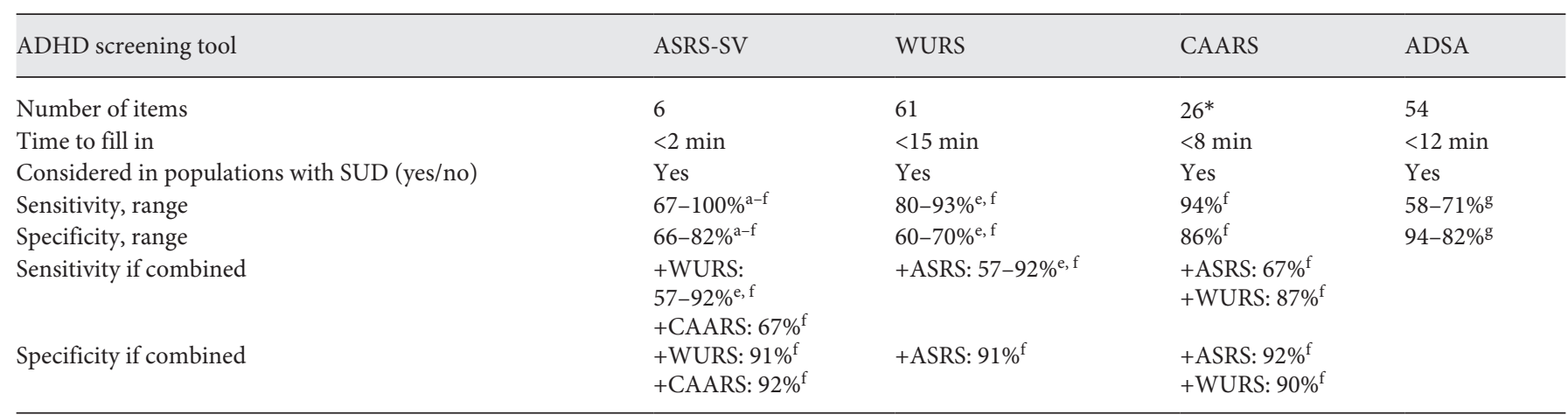

Overview of available screening tools for diagnosing ADHD in adults with comorbid substance use dependence (SUD).

ASRS-SV, Adults ADHD Self-Report Scale Short Version; WURS, Wender Utah Rating Scale; CAARS, Conners' Adult ADHD Rating Scale; ADSA, Attention Deficit Scales for Adults.

* Also available in a long (66 items) and screening (12 items) version.

${ }^{\text {a }}$ van de Glind et al. [51].

${ }^{b}$ Chiasson et al. [52].

${ }^{c}$ Reyes et al. [53].

d Konstenius et al. [54].

${ }^{\mathrm{e}}$ Daigre et al. [55].

${ }^{\mathrm{f}}$ Dakwar et al. [56].

g West et al. [57].

addiction services. The statements below are also valid for ADHD patients with SUD assessed in other mental health services.

Work on this consensus statement started with a Belgian guideline for the treatment of ADHD and SUD, supplemented by a Dutch guideline for the treatment of adults with ADHD and a Dutch Guideline on ADHD-SUD in adolescents [11-14]. No other guidelines were retrieved from our search. The first draft was developed by the Belgian and Dutch representatives of the International Collaboration on ADHD and Substance Abuse (ICASA: FM, CLC, WvdB, GvdG) and was circulated to ICASA members present at meetings in Stockholm (13 experts), Brussels (18 experts) and Budapest (21 experts), where it was discussed. The final statement was written by the Belgian ICASA members (CLC, FM) and adapted and approved by the other members.

\section{Consensus Statement for the Screening and Diagnosis of ADHD and SUD}

\section{Screening}

ADHD has a significant impact on the development and course of SUD and early detection is of key importance for successful treatment. The high prevalence of ADHD in people with SUD, along with the fact that many patients will not spontaneously mention symptoms of ADHD and focus on their SUD problems, makes it important to always screen for the presence of ADHD. Several screening tools are available for use in adults with $\mathrm{ADHD}$ and SUD comorbidity. In Table 1, we present an overview of the currently used and validated screening tools.

The Short Version of the Adult ADHD Self-Report Scale (ASRS-SV) screener is currently the most widely used and investigated screening tool in individuals with ADHD and comorbid SUD, with good sensitivity and specificity across studies (Table 1). Similarly, screening with Conners' Adult ADHD Rating Scale, Wender Utah Rating Scale, or Attention Deficit Scales for Adults also allows for a good recognition of possible ADHD (Table 1), but they take longer to complete. A positive screening result should always lead to further diagnostic assessments. Nevertheless, up to $20 \%$ of patients with ADHD are missed when using a single screener. Therefore, if time and budget allow this within the health care service, we recommend combining 2 screening instruments. Patients clinically suspected of having ADHD - even with a negative screening result - should always receive an extended diagnostic assessment.

\section{Difficulties and Concerns When Diagnosing Adult}

ADHD in Patients with SUD

The risk of both under-diagnosing and over-diagnosing ADHD in adult SUD populations is a point of concern. The strictness of the DSM-IV (Diagnostic and Statistical Manual of Mental Disorders, 4th Edition) criteria, 
maintaining that ADHD had to occur independent of other disorders, could complicate the diagnosis of ADHD in adults with SUD and lead to under-diagnosis [15]. Also, adult patients with SUD often have more difficulties in remembering the early history of ADHD symptoms [15]. Therefore, ADHD can erroneously be overlooked in this population. Additionally, if an individual with SUD was not diagnosed with ADHD as a child, it is less likely that the behaviour as an adult will be linked to ADHD, because these are associated with intoxication, withdrawal or the (interpersonal) consequences of substance abuse [15]. As ADHD is mostly not the reason why patients with SUD seek treatment [16], it is the clinician's task to address and recognize ADHD in these patients. Finally, many consequences of ADHD (job loss, poor school performance) are also seen in patients with SUD, and they can be erroneously attributed to substance abuse. Adults with ADHD are often dealing with the symptoms for many years and have developed compensation strategies that limit the impact and/or mask the symptoms [17]. Less frequent, but important, is the problem of over-diagnosing ADHD in SUD patients, that is, when SUD symptoms are erroneously attributed to ADHD. It is important that ADHD symptoms also occur in settings, situations and stages of life without substance use. Overdiagnosing can also occur when the continuity of symptoms from childhood to adulthood is overlooked or when substance-induced symptoms or withdrawal symptoms are perceived as ADHD symptoms. Therefore, it is recommended that developmental history, psychiatric comorbidity and family history are all addressed. Finally, patients may exaggerate ADHD symptoms to obtain prescription stimulants for abuse or diversion. For all these reasons, a follow-up evaluation of ADHD symptoms during SUD treatment is recommended in order to reduce the risk of misdiagnosis [18].

Diagnosis should consist of the following necessary steps similar to those needed for the diagnosis of ADHD in an adult population without SUD: an examination of current ADHD symptoms, ADHD symptoms during childhood, family history of ADHD and SUD, school and occupational history, marriage, physical signs and comorbidity [19]. It is important to include environmental and psychosocial factors in the broad sense of the term in the diagnostic process. These are factors that could have protective or risk-enhancing effects on the functioning of the individual. Moreover, to be diagnosed with ADHD according to DSM-5, some symptoms are required to have occurred before age 12 . For confirmation, a collateral history can be taken with someone who knows the patient well (e.g., parents or siblings).
Who Is Qualified to Make an ADHD Diagnosis?

An essential requirement for a correctly performed ADHD diagnosis is that the diagnostician must be knowledgeable and competent. The literature argues towards a targeted training on the dual-diagnosis of ADHD and SUD [20]. The expert group recommends that a physician or clinical psychologist can make the diagnosis of ADHD in SUD patients, provided he/she has received extensive training on the differential diagnosis of ADHD, has experience in addiction care, and has experience with adult ADHD populations.

\section{When Should the Diagnostic Process Start?}

The expert group suggests starting the diagnostic process as soon as possible: (i) when there are no serious withdrawal symptoms and (ii) when there is no serious intoxication. Clinical history taking, observation and screening can be started earlier. If feasible, one can include a period of abstinence, determined by the clinical experience of the diagnostician and taking into account the setting in which the patient is treated and the drug(s) abused. The preliminary diagnosis must be verified in the course of treatment, as the presentation of ADHD symptoms can change with successful SUD treatment. A good follow-up prevents over- or under-diagnosis and it is therefore essential to continue monitoring the patient.

\section{Current ADHD Symptoms and Clinical History}

Taking in Adults with SUD

The diagnosis of ADHD should be part of a medicalpsychiatric examination, and include a thorough investigation of current symptoms (using diagnostic instruments), (collateral) history taking (elements from childhood, family history, educational and occupational history, marriage, etc.) and additional examinations (for comorbidity and differential diagnosis).

Collateral history taking on current and childhood symptoms is essential to obtain information from another perspective. Memories are not always easy to recall, and involving family members (and significant others) may be helpful. Also, parents' memory is not always reliable [21]. In a population of adults with SUD, obtaining information regarding past experiences is even more difficult. The patient may be reluctant to share their contact information or the family may be unwilling to cooperate. In such cases, objective childhood data can be obtained through, for example, school reports and by paying particular attention to comments made by former teachers [19]. Symptoms associated with the patient's substance use may be erroneously identified as ADHD symptoms,
Crunelle et al. 
and it is therefore recommended to focus on alcohol- and drug-free periods in the patient's life.

Diagnostic interviews such as Conners' Adult ADHD Diagnostic Interview for the DSM-IV (CAADID) can be used to aid the diagnosis. The CAADID is often used as the gold standard for the diagnosis of adult ADHD in patients with SUD [22]. The Diagnostic Interview for ADHD in adults (DIVA) can be administered in the presence of the partner and relatives to simultaneously collect past history and collateral past history information but is not yet validated in adults with SUD. The Psychiatric Research Interview for Substance and Mental Disorders (PRISM) is a semi-structured interview that focuses on comorbid psychiatric diagnoses and is based on the DSM-IV criteria for axis 1 and II disorders, including ADHD [22]. In 80 patients with SUD (40 with and 40 without ADHD), the PRISM had a sensitivity of $80 \%$ and a specificity of $88 \%$ for the detection of ADHD, compared to CAADID [22].

\section{Assessing (History of) Substance Abuse in Adult ADHD Patients}

Personal interview is the best way to establish a history of substance abuse and the related disruptions in different life domains (social, schooling, work). This may be supplemented by a toxicological confirmation, for example, in urine, blood or hair samples.

Two generally accepted screening instruments are the Drug Abuse Screening Test and the Alcohol Use Disorders Identification Test. Both were investigated for their construct validity and reliability and results indicate they are acceptable screening instruments in adults with ADHD [23].

\section{Consensus Statement for the Treatment of ADHD and SUD}

\section{Treatment of ADHD in Adults with SUD}

Proper treatment of ADHD in people with SUD comprises several components, including psycho-education, pharmacotherapy, individual and/or group cognitive and behavioral therapy, as well as peer support [24]. In adults with ADHD and SUD, research suggests the usefulness of combined pharmacotherapy and psychotherapy [25-26].

The treatment of ADHD should be integrated in the treatment of SUD and vice versa [26]. This is important because ADHD symptoms can interfere with SUD treatment and/or SUD can complicate the treatment of ADHD. It is advisable to first start SUD treatment, followed by ADHD treatment as soon as possible thereafter [27]. When the SUD is too severe, brief residential treatment maybe appro-

Consensus ADHD-SUD priate. One should keep in mind that effective treatment of ADHD would usually not result in improvement of SUD, hence the importance of effectively treating both disorders.

\section{Pharmacotherapy}

Studies show that medication is moderately effective in reducing ADHD symptoms in patients with ADHD-SUD comorbidity (mean standardized effect size $0.40-0.50$ ). On the other hand, medication has more positive effects when combined with psychotherapy, while ADHD pharmacotherapy by itself is generally not effective in reducing the use of substances and is associated with a higher frequency of adverse effects and treatment discontinuation [7,27].

Non-randomized studies showed some promise for the improvement of both ADHD and SUD, but the more recent double blind and placebo-controlled trials were less positive. Open trials in ADHD-SUD patients provided some evidence for the effectiveness of bupropion to reduce ADHD symptoms, but this is contradicted in a small controlled study showing no effect over placebo in the treatment of ADHD with SUD [28]. In several studies, ADHD symptoms seemed to show improvement across all groups, indicating that there is an important placebo effect associated with either expectation and/or the effect of the psychotherapy provided in all treatment conditions.

Controlled randomized trials with short- and longacting standard doses of methylphenidate either show to neither improve ADHD and SUD symptoms or to improve ADHD symptoms but not drug use [28-31]. However, caution should be taken with the interpretation of negative results, because some of these studies showed promise with regard to SUD outcomes in secondary analyses [31-33]. Two studies with higher doses of methylphenidate (up to $180 \mathrm{mg}$ /day) showed a decrease in ADHD symptoms and a decrease in the reinforcing effects and the use of cocaine and amphetamines (and other drugs) in adult stimulant-dependent ADHD patients [34-35]. Also, robust doses of extended-release mixed amphetamine (60 and $80 \mathrm{mg} /$ day) showed substantial reductions in both ADHD and drug use in cocaine-dependent patients with ADHD [35]. Pemoline had a significant effect on ADHD symptoms, but not on drug use [33]. Atomoxetine resulted in a significant reduction on ADHD symptoms, and was associated with a decrease in alcohol craving and consumption [32].

\section{Safety of Pharmacological ADHD Treatment in}

Adults with Comorbid SUD

Prescribing stimulants to individuals with SUD remains controversial and many clinicians are reluctant to prescribe 
proper ADHD treatment in individuals with SUD. While stimulants can be effective in treating those with ADHD and SUD, particularly at higher doses [34-35], there is the clear risk of misuse and diversion of stimulants and this cannot be overstated. It is also important to recognize that this risk may differ by patient characteristics. Two groups that are at substantial risk include adolescents and young adults [36], although adults are not immune from misusing or abusing their medication. Importantly, long-acting formulations, particularly osmotic-release oral system formulations of methylphenidate (OROS-MPH) and lisdexamphetamine, have considerably lower rates of misuse and diversion compared to immediate-release preparations [37].

Adverse events are not increased in ADHD patients with SUD compared to when giving stimulants to ADHD patients without SUD [38]. The literature does not mention severe complications or increases in substance abuse with prescribing central stimulants in this patient population [27]. However, a dose-dependent interaction between disulfiram and methylphenidate resulting in psychotic episodes has been described [39]. Finally, the use of stimulant treatment for ADHD does not precipitate the onset of SUD in adults without previous SUD [40]. In SUD patients, treatment of ADHD can be useful to reduce ADHD symptoms without worsening the SUD [41] and should not be avoided.

Regarding prevention of SUD, stimulant treatment of children with ADHD may have some protective effects on the development of SUD if children receive stimulant treatment from a young age and for a long enough time [42].

Taken together, clinicians need to be circumspect when prescribing stimulants, particularly among highrisk populations. However, abuse and diversion can be reduced by close monitoring, use of longer acting formulations, and engaging in a discussion with patients on the importance of safeguarding their medication. As with any prescription of controlled substances, the clinician must weigh the risk of abuse/diversion versus the medication's potential therapeutic benefit. After careful deliberation of these factors, the prescriber must use his/her clinical judgement regarding whether it is reasonable to initiate or to continue stimulant pharmacotherapy.

\section{Treatment Retention}

Treatment retention is an important difficulty in the treatment of SUD, particularly in SUD patients with ADHD [5]. Patients often regard ADHD treatment as a sign of recognition of their problems, potentially increasing treatment retention. Under-diagnosing ADHD in SUD patients may result in problems with compliance and SUD treatment retention. Medication that takes ef- fect only after a few weeks (e.g., atomoxetine) may also be a reason for continued substance use and drop out.

In patients with $\mathrm{ADHD}$, severity of SUD - rather than the mere presence of ADHD - is a predictive factor for treatment outcome [43]. Adult ADHD-SUD patients treated with methylphenidate have better retention in treatment than ADHD patients who receive placebo [44]. Higher doses of methylphenidate are also associated with better long-term treatment adherence [45].

\section{Non-Pharmacological Interventions}

There are few studies on non-pharmacological treatment of patients with both ADHD and SUD. Clinicians should consider therapy with a focus on overlapping symptoms as part of a multimodal treatment approach including psychotherapy and medication [25-26, 46]. Data collection of the first randomized controlled trial comparing integrated cognitive behavioral therapy (ICBT) with standard CBT for patients with both SUD and ADHD has been finalized and 2 case reports are available, while results are expected in 2018 [47]. In a qualitative study, patients with ADHD and SUD mention their wish for a coaching attitude [48]. A dialectic behavioral therapy-based skills training for adults with ADHD and SUD is also described, with varying results regarding efficacy [49]. A Belgian guideline that presents a practical approach for the non-pharmacological treatment of adult ADHD in patients with SUD was published [50]. Other non-pharmacological interventions, such as individual coaching, structured skills training, dialectic behavioural therapy and mindfulness-based therapy are not yet investigated in the context of ADHD-SUD comorbidity.

\section{Discussion}

Given the high prevalence of ADHD in SUD patients, all patients in addiction care should be screened for the presence of adult ADHD. The ASRS, the Wender Utah Rating Scale and the Conners' Adult ADHD Rating Scale have been sufficiently validated as screeners. If the screening result is positive or if ADHD is clinically suspected, a physician or clinical psychologist with specialist training on the differential diagnosis of ADHD and experience in addiction care should initiate a more extensive diagnostic examination. The use of questionnaires and semi-structured interviews can be useful for diagnosis. To date, no semi-structured ADHD interview has been sufficiently validated in a population with ADHD and SUD. Diagnostic examination should be complemented with observation and (collateral) history taking, including a good fol-
Crunelle et al. 
Table 2. Summary of key points from the consensus statement

Level of Recommendation evidence* level*

Diagnosis

The ASRS is the most extensively tested screener and performs well as a screening tool for ADHD in adults with SUD, $\quad 2+$ but some other instruments have also shown promise (e.g., WURS).

The diagnostic process should be started as soon as possible, keeping in mind that the diagnostic process is a continuous $3 \quad \mathrm{D}$ one. A good follow-up prevents over- or under-diagnosis of ADHD in patients with SUD.

A physician or clinical psychologist can make the diagnosis of ADHD provided that he/she has received extensive
training on the differential diagnosis of ADHD, has experience in addiction care, and has experience with adult ADHD populations.

Clinicians should consider the diagnosis of ADHD unspecified and consider ADHD treatment when adult ADHD 4 symptoms are present with sufficient severity.

If possible, involve the patients' parents, partner and/or relatives to assess former and current symptomatology and 3 assess functional impairments. Additional information can be gathered from school records and comments added by former teachers.

\begin{tabular}{l} 
The diagnostic process should include current and past substance use (frequency and quantity of use, social context). $3 \quad$ C \\
\hline Focus on drug- and alcohol-free periods in the patient's life during (collateral) history taking. \\
\hline
\end{tabular}

Treatment

Consider adequate medical treatment of both ADHD and SUD.

Always consider a combination of psychotherapy and pharmacotherapy.

Integrate the ADHD and other psychiatric comorbidity treatment with SUD treatment as soon as possible.

Psychotherapy, preferentially targeting the combination of ADHD and SUD, should be considered.

Long-acting methylphenidate, extended-release amphetamines, and atomoxetine are effective in the treatment of comorbid ADHD and SUD, and up-titration to higher dosages may be considered in some patients. The abuse potential

is limited with long-acting agents.

Caution and careful clinical management is needed to prevent abuse and diversion of prescribed stimulants.

$2 \quad \mathrm{C}$

$2 \quad \mathrm{D}$

2 C

3 C

$3 \quad \mathrm{C}$

D

C

\footnotetext{
Overview of the summary points from the consensus statement on the screening, diagnosis, and treatment of adult ADHD in individuals with comorbid SUD.

* The recommendations are assigned a rating according to the quality of the evidence on which they are based, using the SIGN grading system based on level of evidence ranging from 1++ (meta-analyses or systemic reviews of RCTs) to 4 (expert opinion; SIGN, 2001). A, at least one meta-analysis, systematic review, or RCT rated as 1++, and directly applicable to the target population or a body of evidence consisting principally of studies rated as $1+$, directly applicable to the target population, and demonstrating overall consistency of results; B, body of evidence including studies rated as $2++$, directly applicable to the target population, and demonstrating overall consistency of results or Extrapolated evidence from studies rated as 1++ or 1+; C, A body of evidence including studies rated as $2+$, directly applicable to the target population and demonstrating overall consistency of results or Extrapolated evidence from studies rated as 2++; D, evidence level 3 or 4 or Extrapolated evidence from studies rated as $2+$.
}

low-up to reduce the risk of over- or under-diagnosis. Partner and siblings can provide information on the patient's former and current symptoms, but also school records and comments by former teachers can be useful. An extensive description of the patient's current and past substance use can best be determined by focusing on drug- and alcohol-free periods in the patient's life.

This consensus statement refers to the diagnosis and treatment of ADHD among treatment-seeking SUD patients. However, more than one third of these patients are also affected by other comorbidities [4], which mostly have been clinically diagnosed or even systematically evaluated even before ADHD is considered. For example, van Emmerik-van Oortmerssen et al. [4] showed that having an ADHD diagnosis as a SUD patient doubles the likelihood of having an additional psychiatric diagnosis to more than 75\%, making ADHD a highly relevant risk factor for additional comorbidities. Therefore, detecting and treating ADHD is the focus of this consensus statement.

Treatment of ADHD patients with SUD remains a challenge. Controlled trials show moderate improvements in ADHD symptoms upon pharmacological 
ADHD treatment in ADHD-SUD patients. However, pharmacotherapy should not be avoided and should be critically encouraged in patients with ADHD and SUD with a preference for high doses of long-acting stimulants in ADHD patients with stimulant use disorders or atomoxetine in patients with alcohol use disorder. Treatment of ADHD can be useful to reduce ADHD symptoms without worsening the SUD. One should consider treating both ADHD and SUD with their own medication simul- taneously, that is, for patients with ADHD and an alcohol use disorder, one may consider treatment with atomoxetine and with naltrexone, nalmafene, acomprosate or topiramate. A multimodal integrated approach, combining pharmacotherapy (for ADHD and SUD) with a nonpharmacological intervention that targets both the $\mathrm{ADHD}$ and SUD, such as an integrated CBT, is warranted but further research is needed. Table 2 summarizes the key diagnostic and treatment recommendations.

\section{References}

1 Kaye S, Ramos-Quiroga JA, van de Glind G, Levin FR, Faraone SV, Allsop S, Degenhardt L, Moggi F, Barta C, Konstenius M, Franck J, Skutle A, Bu ET, Koeter MW, Demetrovics Z, Kapitány-Fövény M, Schoevers RA, van Emmerik-van Oortmerssen K, Carpentier PJ, Dom G, Verspreet S, Crunelle CL, Young JT, Carruthers S, Cassar J, Fatséas M, Auriacombe M, Johnson B, Dunn M, Slobodin O, van den Brink W: Persistence and dubtype stability of ADHD among substance use disorder treatment seekers. J Atten Disord 2016;pii:1087054716629217.

2 Fatséas M, Hurmic H, Serre F, Debrabant R, Daulouède JP, Denis C, Auriacombe M: Addiction severity pattern associated with adult and childhood attention deficit hyperactivity disorder (ADHD) in patients with addictions. Psychiatry Res 2016;246:656-662.

3 Young JT, Carruthers S, Kaye S, Allsop S, Gilsenan J, Degenhardt L, van de Glind G, van den Brink W, Preen D: Comorbid attention deficit hyperactivity disorder and substance use disorder complexity and chronicity in treatment-seeking adults. Drug Alcohol Rev 2015;34:683-693.

4 van Emmerik-van Oortmerssen $K$, van de Glind G, Koeter MW, Allsop S, Auriacombe M, Barta C, Bu ET, Burren Y, Carpentier PJ, Carruthers S, Casas M, Demetrovics Z, Dom G, Faraone SV, Fatseas M, Franck J, Johnson $B$, Kapitány-Fövény $M$, Kaye $S$, Konstenius M, Levin FR, Moggi F, Møller M, RamosQuiroga JA, Schillinger A, Skutle A, Verspreet S; IASP research group, van den Brink W, Schoevers RA: Psychiatric comorbidity in treatment-seeking substance use disorder patients with and without attention deficit hyperactivity disorder: results of the IASP study. Addiction 2014;109:262-272.

5 Levin FR, Evans SM, Vosburg SK, Horton T, Brooks D, Ng J: Impact of attention-deficit hyperactivity disorder and other psychopathology on treatment retention among cocaine abusers in a therapeutic community. Addict Behav 2004;29:1875-1882.

6 Kronenberg LM, Goossens PJ, van Etten DM, van Achterberg T, van den Brink W: Need for care and life satisfaction in adult substance use disorder patients with and without atten- tion deficit hyperactivity disorder (ADHD) or autism spectrum disorder (ASD). Perspect Psychiatr Care 2015;51:4-15.

7 Cunill R, Castells X, Tobias A, Capellà D: Pharmacological treatment of attention deficit hyperactivity disorder with co-morbid drug dependence. J Psychopharmacol 2015;29:15-23.

8 Charach A, Yeung E, Climans T, Lillie E: Childhood attention-deficit/hyperactivity disorder and future substance use disorders: comparative meta-analyses. J Am Acad Child Adolesc Psychiatry 2011;50:9-21.

9 van Emmerik-van Oortmerssen K, van de Glind G, van den Brink W, Smit F, Crunelle CL, Swets M, Schoevers RA: Prevalence of attention-deficit hyperactivity disorder in substance use disorder patients: a meta-analysis and meta-regression analysis. Drug Alcohol Depend 2012;122:11-9.

10 van de Glind G, Konstenius M, Koeter MWJ, van Emmerik-van Oortmerssen K, Carpentier PJ, Kaye S, Degenhardt L, Skutle A, Franck J, Bu ET, Moggi F, Dom G, Verspreet S, Demetrovics Z, Kapitány-Fövény M, Fatséas M, Auriacombe M, Schillinger A, Møller M, Johnson B, Faraone SV, Ramos-Quiroga JA, Casas M, Allsop S, Carruthers S, Schoevers RA, Wallhed S, Barta C, Alleman P; IASP Research Group, Levin FR, van den Brink W: Variability in the prevalence of adult ADHD in treatment seeking substance use disorder patients: results from an international multi-center study exploring DSM-IV and DSM-5 criteria. Drug Alcohol Depend 2014;134:158-166.

11 Matthys F, Möbius D, Stes S, et al: Good Clinical Practice in de Herkenning en Behandeling van ADHD bij (jong)volwassenen met verslavingsproblemen. Richtlijnen voor de klinische praktijk. Brussel, VAD, 2010.

12 Matthys F, Soyez V, van den Brink W, Joostens P, Tremmery S, Sabbe B: Barriers to implementation of treatment guidelines for ADHD in adults with substance use disorder. J Dual Diagn 2014;10:130-138.

13 http://www.nvvp.net/stream/richtlijn-adhdbij-volwassenen-fase-1-diagnostiek-en-medicamenteuze-behandeling-2015 (accessed March 16, 2017).

14 Hendriks V, de Jong C: Richtlijn ADHD en middelengebruik bij adolescenten: screening, diagnostiek en behandeling in de jeugd-GGZ en jeugdverslavingszorg. Perspectief Uitgevers, 2014;ISBN:9789492121134.

15 Levin FR, Upadhyaya HP: Diagnosing ADHD in adults with substance use disorder: DSMIV criteria and differential diagnosis. J Clin Psychiatry 2007;68:e18.

16 Dakwar E, Levin FR, Olfson M, Wang S, Kerridge $\mathrm{B}$, Blanco $\mathrm{C}$ : First treatment contact for ADHD: predictors of and gender differences in treatment seeking. Psychiatr Serv 2014;65: 1465-1473.

17 Barkley RA, Brown TE: Unrecognized attention-deficit/hyperactivity disorder in adults presenting with other psychiatric disorders. CNS Spectr 2008;13:977-984.

18 Fatseas M, Debrabant R, Auriacombe M: The diagnostic accuracy of attention-deficit/hyperactivity disorder in adults with substance use disorders. Curr Opin Psychiatry 2012;25: 219-225.

19 Adler L, Cohen J: Diagnosis and evaluation of adults with attention-deficit/hyperactivity disorder. Psychiatr Clin North Am 2004;27: 187-201

20 Martinez-Raga J, Szerman N, Knecht C, de Alvaro R: Attention deficit hyperactivity disorder and dual disorders. Educational needs for an underdiagnosed condition. Int J Adolesc Med Health 2013;25:231-243.

21 Moffitt TE, Houts R, Asherson P, Belsky DW, Corcoran DL, Hammerle M, Harrington $\mathrm{H}$, Hogan S, Meier MH, Polanczyk GV, Poulton R, Ramrakha S, Sugden K, Williams B, Rohde LA, Caspi A: Is adult ADHD a childhood-onset neurodevelopmental disorder? evidence from a four-decade longitudinal cohort study. Am J Psychiatry 2015;172:967-977.

22 Ramos-Quiroga JA, Díaz-Digon L, Comín M, Bosch R, Palomar G, Chalita JP, Roncero C, Nogueira M, Torrens M, Casas M: Criteria and concurrent validity of adult ADHD section of the psychiatry research interview for substance and mental disorders. J Atten Disord 2015;19:999-1006.

23 McCann BS, Simpson TL, Ries R, Roy-Byrne $\mathrm{P}$ : Reliability and validity of screening instruments for drug and alcohol abuse in adults seeking evaluation for attention-deficit/hyperactivity disorder. Am J Addict 2000;9:1-9. 
24 Goossensen MA, van de Glind G, Carpentier PJ, Wijsen RM, van Duin D, Kooij JJ: An intervention program for $\mathrm{ADHD}$ in patients with substance use disorders: preliminary results of a field trial. J Subst Abuse Treat 2006; 30:253-259.

25 Zulauf CA, Sprich SE, Safren SA, Wilens TE: The complicated relationship between attention deficit/hyperactivity disorder and substance use disorders. Curr Psychiatry Rep 2014; 16:436.

26 Torrens M, Rossi PC, Martinez-Riera R, Martinez-Sanvisens D, Bulbena A: Psychiatric comorbidity and substance use disorders: treatment in parallel systems or in one integrated system? Subst Use Misuse 2012;47:10051014.

27 Wilens TE, Morrison NR: Substance-use disorders in adolescents and adults with ADHD: focus on treatment. Neuropsychiatry (London) 2012;2:301-312.

28 Levin FR, Evans SM, Brooks DJ, Kalbag AS, Garawi F, Nunes EV: Treatment of methadone-maintained patients with adult ADHD double-blind comparison of methylphenidate, bupropion and placebo. Drug Alcohol Depend 2006;81:137-148.

29 Riggs PD, Winhusen T, Davies RD, Leimberger JD, Mikulich-Gilbertson S, Klein C, Macdonald M, Lohman M, Bailey GL, Haynes L, Jaffee WB, Haminton N, Hodgkins C, Whitmore E, Trello-Rishel K, Tamm L, Acosta MC, Royer-Malvestuto C, Subramaniam G, Fishman M, Holmes BW, Kaye ME, Vargo MA, Woody GE, Nunes EV, Liu D: Randomized controlled trial of osmotic-release methylphenidate with cognitive-behavioral therapy in adolescents with attention-deficit/hyperactivity disorder and substance use disorders. J Am Acad Child Adolesc Psychiatry 2011;50:903-914.

30 Schubiner H, Saules KK, Arfken CL, Johanson CE, Schuster CR, Lockhart N, Edwards A, Donlin J, Pihlgren E: Double-blind placebocontrolled trial of methylphenidate in the treatment of adult ADHD patients with comorbid cocaine dependence. Exp Clin Psychopharmacol 2002;10:286-294.

31 Winhusen TM, Somoza EC, Brigham GS, Liu DS, Green CA, Covey LS, Croghan IT, Adler LA, Weiss RD, Leimberger JD, Lewis DF, Dorer EM: Impact of attention-deficit/hyperactivity disorder (ADHD) treatment on smoking cessation intervention in ADHD smokers: a randomized, double-blind, placebo-controlled trial. J Clin Psychiatry 2010;71: 1680-1688.

32 Wilens TE, Adler LA, Weiss MD, Michelson D, Ramsey JL, Moore RJ, Renard D, Brady KT, Trzepacz PT, Schuh LM, Ahrbecker LM Levine LR; Atomoxetine ADHD/SUD Study Group: Atomoxetine treatment of adults with ADHD and comorbid alcohol use disorders. Drug Alcohol Depend 2008;96:145-154.

33 Riggs PD, Hall SK, Mikulich-Gilbertson SK, Lohman M, Kayser A: A randomized con- trolled trial of pemoline for attention-deficit/ hyperactivity disorder in substance-abusing adolescents. J Am Acad Child Adolesc Psychiatry $2004 ; 43: 420-429$.

34 Konstenius M, Jayaram-Lindström N, Guterstam J, Beck O, Philips B, Franck J: Methylphenidate for attention deficit hyperactivity disorder and drug relapse in criminal offenders with substance dependence: a 24-week randomized placebo-controlled trial. Addiction 2014;109:440-449.

35 Levin FR, Mariani JJ, Specker S, Mooney M, Mahony A, Brooks DJ, Babb D, Bai Y, Eberly LE, Nunes EV, Grabowski J: Extended-release mixed amphetamine salts vs placebo for comorbid adult attention-deficit/hyperactivity disorder and cocaine use disorder: a randomized clinical trial. JAMA Psychiatry 2015;72: 593-602.

36 Austic EA: Peak ages of risk for starting nonmedical use of prescription stimulants. Drug Alcohol Depend 2015;152:224-229.

37 Cassidy TA, Varughese S, Russo L, Budman SH, Eaton TA, Butler SF: Nonmedical use and diversion of ADHD stimulants among U.S. Adults ages 18-49: a National internet survey. J Atten Disord 2015;19:630-640.

38 Kollins SH, Youcha S, Lasser R, Thase ME: Lisdexamfetamine dimesylate for the treatment of attention deficit hyperactivity disorder in adults with a history of depression or history of substance use disorder. Innov Clin Neurosci 2011;8:28-32.

39 Grau-López L, Roncero C, Navarro MC, Casas M: Psychosis induced by the interaction between disulfiram and methylphenidate may be dose dependent. Subst Abus 2012;33: 186-188.

40 Torgersen T, Gjervan B, Rasmussen K, Vaaler A, Nordahl HM: Prevalence of comorbid substance use disorder during long-term central stimulant treatment in adult ADHD. Atten Defic Hyperact Disord 2013;5:59-67.

41 Klassen LJ, Bilkey TS, Katzman MA, Chokka P: Comorbid attention deficit/hyperactivity disorder and substance use disorder: treatment considerations. Curr Drug Abuse Rev 2012;5:190-198.

42 Humphreys KL, Eng T, Lee SS: Stimulant medication and substance use outcomes: a meta-analysis. JAMA Psychiatry 2013;70: 740-749.

43 Tamm L, Trello-Rishel K, Riggs P, Nakonezny PA, Acosta M, Bailey G, Winhusen T: Predictors of treatment response in adolescents with comorbid substance use disorder and attention-deficit/hyperactivity disorder. J Subst Abuse Treat 2013;44:224-230.

44 Kollins SH: Comparing the abuse potential of methylphenidate versus other stimulants: a review of available evidence and relevance to the ADHD patient. J Clin Psychiatry 2003;64: 14-18.

45 Skoglund C, Brandt L, Almqvist C, D’Onofrio BM, Konstenius M, Franck J, Larsson H: Factors associated with adherence to methylphe- nidate treatment in adult patients with attention-deficit/hyperactivity disorder and substance use disorders. J Clin Psychopharmacol 2016;36:222-228.

46 Aviram RB, Rhum M, Levin FR: Psychotherapy of adults with comorbid attention-deficit/ hyperactivity disorder and psychoactive substance use disorder. J Psychother Pract Res 2001;10:179-186.

47 van Emmerik-van Oortmerssen K, Vedel E van den Brink W, Schroevers RA: Integrated cognitive behavioral therapy for patients with substance use disorder and comorbid ADHD: two case presentations. Addict Behav 2015; 45:214-217.

48 Kronenberg LM, Verkerk-Tamminga $R$ Goossens PJ, van den Brink W, van Achterberg T: Personal recovery in individuals diagnosed with substance use disorder (SUD) and co-occurring attention deficit/hyperactivity disorder (ADHD) or autism spectrum disorder (ASD). Arch Psychiatr Nurs 2015;29:242-248.

49 Bihlar Muld B, Jokinen J, Bölte S, Hirvikoski $\mathrm{T}$ : Skills training groups for men with ADHD in compulsory care due to substance use disorder: a feasibility study. Atten Defic Hyperact Disord 2016;8:159-172.

50 Matthys F, Bronckaerts A, Crunelle CL: Managing $\mathrm{ADHD}$ in the presence of substance use disorders. Gompel \& Svacina, 2018. ISBN 978 9463710237.

51 van de Glind G, van den Brink W, Koeter MW, et al: Validity of the Adult ADHD SelfReport Scale (ASRS) as a screener for adult ADHD in treatment seeking substance use disorder patients. Drug Alcohol Depend 2013;132:587-596.

52 Chiasson JP, Stavro K, Rizkallah É, et al Questioning the specificity of ASRS-v1.1 to accurately detect ADHD in substance abusing populations. J Atten Disord 2012;16:661-663.

53 Reyes MM, Schneekloth TD, Hitschfeld MJ, et al: The Clinical Utility of ASRS-v1.1 for Identifying ADHD in Alcoholics Using PRISM as the Reference Standard. J Atten Disord 2016;pii: 1087054716646450.

54 Konstenius M, Larsson H, Lundholm L, et al: An epidemiological study of ADHD, substance use, and comorbid problems in incarcerated women in Sweden. J Atten Disord 2015; 19:44-52

55 Daigre C, Roncero C, Rodríguez-Cintas L, et al: Adult ADHD screening in alcohol-dependent patients using the Wender-Utah Rating Scale and the adult ADHD Self-Report Scale. J Atten Disord 2015;19:328-334.

56 Dakwar E, Mahony A, Pavlicova M, et al: The utility of attention-deficit/hyperactivity disorder screening instruments in individuals seeking treatment for substance use disorders. J Clin Psychiatry 2012;73:e1372-e1378.

57 West SL, Mulsow M, Arredondo R: An examination of the psychometric properties of the attention deficit scales for adults with outpatient substance abusers. Am J Drug Alcohol Abuse 2007;33:755-764. 